\title{
BMJ Open Lived experiences of palliative care among people living with HIV/AIDS: a qualitative study from Bihar, India
}

\author{
Mohit Nair (D) , ${ }^{1}$ Pragya Kumar, ${ }^{2}$ Raman Mahajan (D) , ${ }^{1}$ Amit Harshana, ${ }^{1}$ \\ Kathryn Richardson, ${ }^{1}$ Laura Moreto-Planas, ${ }^{1}$ Sakib Burza ${ }^{1}$
}

To cite: Nair M, Kumar $P$, Mahajan R, et al. Lived experiences of palliative care among people living with HIV/AIDS: a qualitative study from Bihar, India. BMJ Open 2020;10:e036179. doi:10.1136/ bmjopen-2019-036179

- Prepublication history for this paper is available online. To view these files, please visit the journal online (http://dx.doi org/10.1136/bmjopen-2019036179).

Received 04 December 2019 Revised 08 August 2020 Accepted 04 September 2020

Check for updates

(C) Author(s) (or their employer(s)) 2020. Re-use permitted under CC BY-NC. No commercial re-use. See rights and permissions. Published by BMJ.

${ }^{1}$ Medecins Sans Frontieres, New Delhi, Delhi, India

${ }^{2}$ Community \& Family Medicine, All India Institute of Medical Sciences, Patna, Bihar, India

Correspondence to

Dr Sakib Burza;

Sakib.Burza@barcelona.msf.org

\section{ABSTRACT}

Objectives This study aimed to assess the lived experiences of palliative care among critically unwell people living with HIV/AIDS (PLHA), caregivers and relatives of deceased patients. It also aimed to understand the broader palliative care context in Bihar.

Design This was an exploratory, qualitative study which used thematic analysis of semistructured, in-depth interviews as well as a focus group discussion.

Setting All interviews took place in a secondary care hospital in Patna, Bihar which provides holistic care to critically unwell PLHA.

Participants We purposively selected 29 participants: 10 critically unwell PLHA, 5 caregivers of hospitalised patients, 7 relatives of deceased patients who were treated in the secondary care hospital and 7 key informants from community-based organisations.

Results Critically ill PLHA emphasised the need for psychosocial counselling and opportunities for social interaction in the ward, as well as a preference for components of home-based palliative care, even though they were unfamiliar with actual terms such as 'palliative care' and 'end-of-life care'. Critically unwell PLHA generally expressed preference for separate, private inpatient areas for end-of-life care. Relatives of deceased patients stated that witnessing patients' deaths caused trauma for other PLHA. Caregivers and relatives of deceased patients felt there was inadequate time and space for grieving in the hospital. While both critically ill PLHA and relatives wished that poor prognosis be transparently disclosed to family members, many felt it should not be disclosed to the dying patients themselves. Conclusions Despite expected high inpatient fatality rates, PLHA in Bihar lack access to palliative care services. PLHA receiving end-of-life care in hospitals should have a separate dedicated area, with adequate psychosocial counselling and activities to prevent social isolation. Healthcare providers should make concerted efforts to inquire, understand and adapt their messaging on prognosis and end-of-life care based on patients' preferences.

\section{BACKGROUND}

According to the National AIDS Control Organization, the 2017 adult prevalence of HIV in India is estimated at $0.22 \%(0.16 \%-$ $0.30 \%) .^{12}$ Bihar, with a population of

\section{Strengths and limitations of this study}

- We triangulated data between respondents (people living with HIV/AIDS (PLHA), caregivers of hospitalised patients, relatives of deceased patients and key informants from community-based organisations), between methods (using in-depth interviews as well as a focus group discussion) and between interviewers (independent coding).

- Relatives of deceased patients were interviewed within 1 year of patients' death and recall bias may present a potential source of bias in the narratives.

- We strove for theoretical saturation in the study sample as a whole, but did not achieve saturation in each subdemographic of respondents (ie, PLHA, relatives of deceased patients).

- The sample size for this study was limited to 29 respondents.

110 million people, is one of the largest and least economically developed states and is one of six states where AIDS-related deaths continue to rise. ${ }^{1}$

In Bihar, Medecins Sans Frontieres (MSF) provides dedicated and holistic inpatient care to acutely unwell people living with HIV/AIDS (PLHA), a particularly vulnerable group of patients who are severely stigmatised and routinely denied access to healthcare. ${ }^{34}$ Advanced HIV is defined by the WHO as a CD4 cell count $<0.2 \times 10 \wedge 9$ cells/L or a clinical stage 3 or 4 event, and patients with advanced HIV experience mortality rates as high as $40 \% .{ }^{5} 6$ Patients frequently present very late to the service as a result of numerous factors, including lack of awareness of their HIV diagnosis, stigma and routine denials in access to care at other facilities. ${ }^{4}$ MSF is currently the only provider of palliative care services to this vulnerable cohort of patients in the state.

Given the high mortality rate, such patients benefit from effective palliative care, defined by the International Association for Hospice \& Palliative Care as 'active 
holistic care of individuals across all ages with serious health-related suffering due to severe illness, and especially of those near the end of life'. ${ }^{7}$ The WHO considers palliative care to be an essential component of care for PLHA. ${ }^{8}$ The aim of palliative care is to improve quality of life for patients, caregivers and families; core components include addressing physical, emotional and spiritual suffering of patients, and involves the patient, the family, health workers and available community resources. ${ }^{9}$

There are few research studies about palliative care in the Indian literature ${ }^{9-17}$ and none that explicitly focus on PLHA. Most of the evidence around palliative care comes from south India and is limited to cancer management. ${ }^{17-21}$ The scarcity of data from India and most of South Asia makes it difficult to develop an effective understanding of available models of palliative care and patients' expectations of healthcare providers. Khosla $e t$ al suggest that there are several obstacles to improving access to palliative care in India, including population density, geographical diversity, poverty, restrictive policies regarding opioid prescription, limited national palliative care policies and a lack of institutional interest. ${ }^{12}$ In general, awareness among providers and the public with respect to palliative care is quite low in India. ${ }^{22}{ }^{23}$ There are no Indian studies which detail the lived experiences of PLHA who have availed or who require palliative care services. Outside of India, however, palliative care is a recognised and essential component of the HIV care continuum. ${ }^{24-26}$

Other illnesses are better represented in the Indian palliative care literature: for example, Lloyd et al recently conducted a qualitative study assessing the palliative needs of patients who had a stroke in a tertiary care setting in south India. ${ }^{21}$ Despite only including clinicians in the study, the authors found that physical disabilities had the most significant impact on quality of life, and that palliative medicine played a major role in counselling and alleviating caregivers' burden in terms of stroke management and care. ${ }^{21}$ In the global literature, other studies have found hospice services to be perceived as being essential to relief of pain and symptoms. ${ }^{24}$

Understanding how PLHA and caregivers or relatives of critically ill PLHA conceptualise illness and end-oflife care, as well as how they view the roles of healthcare providers, is crucial in developing culturally adapted models of care for such vulnerable populations. Healthcare providers lack guidance on patient expectations regarding privacy, social support mechanisms or satisfaction with current services. As a result, the objectives of this study are twofold:

1. To understand how PLHA, relatives of deceased patients and caregivers of hospitalised patients view palliative care and end-of-life care, and uncover their expectations of healthcare providers.

2. To improve understanding of the palliative care ecosystem in Bihar, especially for vulnerable groups such as PLHA.

\section{MATERIALS AND METHODS}

\section{Study design and population}

This was an exploratory, qualitative study design, which used semistructured in-depth interviews (IDIs) and a focus group discussion (FGD). IDIs were used due to the sensitive nature of inquiry and concerns around participants' confidentiality. Participants such as patients, caregivers or relatives of deceased patients were unlikely to feel comfortable participating openly in a group discussion when discussing grieving practices or perceptions of treatment. The study population included recently discharged PLHA, relatives of deceased patients who had received treatment and caregivers of hospitalised patients being treated at the time of study in the advanced HIV inpatient ward at a governmental secondary care hospital in Patna. Caregivers accompanied recently hospitalised patients, whereas relatives of deceased patients were interviewed after they were no longer caregivers (the patient had already passed away at least 2 months prior).

In contrast, the FGD format was used with communitybased organisations (CBOs) since the intention was to understand the overall ecosystem of palliative care in Bihar, and the group was comprised of multiple members from the same organisation. Key informants from CBOs that worked on HIV or palliative care were also included in the sampling frame. These CBOs did not work in the government secondary care hospital, and hence, provided context around the palliative care situation more broadly in Bihar. We interviewed a female representative from Jiv Daya Foundation, an organisation funding palliative care programmes across India, and conducted an FGD with women from two different community-based organisations: National Coalition of PLHA in India and Patna Network for PLHA Society.

\section{Data collection}

Data collection took place over a 1-month period in April-May 2019. All interviews happened face-to-face using a semistructured interview guide after obtaining written informed consent. Interviews were audio recorded with each interview lasting approximately 30-45 min. Interviewers were able to speak a host of local languages, including Bhojpuri, Maghi, Maithli and Hindi, and research assistants were used for translation during interviews where needed. In order to minimise recall bias, PLHA and caregivers of hospitalised patients who had been discharged from the advanced HIV in-patient department of the MSF facility within the previous month were recruited. Relatives of deceased patients were recruited using a list of all patients' deaths over the last 1-year period (from the date of interview). Relatives of deceased patients were initially contacted by telephone and informed about the study. If the relative indicated interest in participating in the study, they were asked to provide a convenient time for the interview. Relatives of patients who had passed away within the last 2 months were avoided in cognisance of the grieving period and in an effort to avoid retraumatisation. A counsellor was 
available at all times to support any patients or relatives who wished to receive psychological support.

Key informants from CBOs were purposively sampled after a thorough literature review and mapping exercise to identify PLHA advocacy groups or other organisations working in the field of advanced HIV and palliative care in Bihar. Separate interview guides were used for each subgroup and participants were purposively and continuously sampled until saturation was attained.

The interview guide (online supplemental file 1) was designed based on a literature review which generated substantial previous cancer research exploring lived experiences of palliative care in high-income settings. These were used to devise similar open-ended questions that were adapted and revised through pilot testing. Each subgroup of participants (ie, relatives of deceased patients, caregivers) had a separate interview guide that probed on specific areas: for instance, with relatives of deceased patients, we were particularly interested in understanding grieving processes and how serious illnesses were dealt with at the community level. In contrast, with CBOs, we were more interested in exploring the level, awareness and potential appropriateness of palliative care provision for PLHA in Bihar. The tool was pilot tested with 10 respondents prior to interviews, but it was intentionally designed as a flexible tool that could be revised iteratively as needed with each subsequent interview.

\section{Data storage}

Audio recordings were stored in a password-protected folder that was only accessible to primary interviewers. These recordings were deleted once the interviews had been transcribed verbatim, de-identified and translated into English, in order to protect the confidentiality of all participants and minimise the risk of confidentiality breaches. De-identified transcripts were stored securely, in order to be accessible for a further 6 years.

\section{Data analysis}

Qualitative data from interviews were transcribed verbatim and translated from Hindi or other local languages (Bhojpuri, Maghi, Maithli) into English by research assistants who were trained in transcription and translation. Following data transcription, translation and entry into NVivo V.11 qualitative data analysis software, two researchers read and reread each transcript and engaged in an inductive, thematic analysis of the data. Emergent codes and categories were identified and compared with subsequent areas of inquiry. Data collection and analysis happened concurrently and interview guides were revised as needed to draw on new areas of inquiry. As part of the thematic analysis, the researchers identified codes and categories pertaining to experiences of care and treatment, analysed patterns and relationships between categories, and engaged in a latent analysis of data. The final coding framework was inductively derived by consensus between the two researchers. Quality assurance was built into the process through pilot testing and iterative development of the interview guide, as well as independent and comparative coding of transcripts. Translation accuracy was assured through back-translation of sections of randomly selected transcripts from English to local languages prior to formal data analysis.

\section{Ethical considerations}

All respondents were interviewed in a private room within the hospital, and each respondent was provided with an information sheet. All respondents provided written informed consent prior to participation in the study. All patients and their family members were compensated for loss of daily wages (300 Indian rupees per participant).

\section{Patients and public involvement}

Patients or the public were not involved in the design, or conduct, or reporting, or dissemination plans of our research.

\section{RESULTS}

Interviews were conducted with 7 relatives of deceased patients, 10 critically unwell PLHA and 5 caregivers of hospitalised patients who had accompanied critically unwell patients. We attempted to reach out to 12 relatives of deceased patients, but 1 had unfortunately died, 2 had untraceable contact information and 2 others declined to participate in the study due to distance from the study site. The average age of all participants was approximately 32 years.

\section{Fear of death and the need for a separate ward for dying patients}

Some PLHA who were critically ill and several relatives of deceased PLHA expressed a preference for a private room for end-of-life care as they had witnessed other deaths within the facility and expressed discomfort with the process. Many PLHA claimed that observing dying patients made them even more anxious: "it causes a lot of fear and concern when you look at those patients. The ones who are healthy will also become anxious" (male patient in his 40s). This particular patient's wife similarly reported that she usually shielded her husband from news about deaths to keep him motivated: "I did not tell him about the deaths of any other patients who have passed away here...because he used to think that all the time in his head and cry- and he asks: will I also die one day like this? He gets very tense thinking about this. This is why I do not tell him" (female caregiver in her 30s).

Relatives of deceased patients confirmed that witnessing deaths had indeed caused trauma for other PLHA: "with this disease, some are coming for the first time... and some of them are coming for the last time. So if you keep all the people, they will become really worried and anxious and think I will also become like that one day" (man in his 30 s, relative of deceased patient).

However, respondents desired a balance between a separation from witnessing the process of death and ensuring 
adequate social interactions with other residents: "if they are separated, it would be difficult for us to meet and give them companionship. Only doctors and nurses will visit them...it is nice the way things are. Because they talk to me, and I talk to them. If someone has to stay alone [in a separate ward], then you feel isolated and the heart... feels uneasy" (female patient in her 20s).

\section{Transparency regarding a poor prognosis}

Relatives of deceased patients deeply regretted not having had meaningful last moments with their loved ones before their death. Many reported that the prognosis should be disclosed to patients and relatives, so the patient has a chance to meet loved ones: "The only thing that makes me sad is that I was not informed beforehand of my mother's condition. If I knew ahead of time that she was going to die, I could have let my sister talk to my mother on her deathbed" (male teenager, relative of deceased patient). This particular relative picked up on social cues by doctors even though he was not directly informed about the prognosis: "they knew of my mother's prognosis. I could understand a little from their discussions, especially the doctor who used to talk to others in English...they had definitely come to know that this patient wouldn't survive. But they never told me" (male teenager, relative of deceased patient).

PLHA mostly wished that the prognosis should be transparently disclosed to family members, but a limited number considered that a terminal prognosis should not be disclosed to dying patients themselves. Many PLHA interviewed after they had been critically ill themselves reported that transparent disclosure of prognosis to dying patients would make them anxious or even kill them, and that this should never be done. Instead, some PLHA claimed that the prognosis should be disclosed only to family members: "it would be better if only the family members are informed, and not the patient actually. The patient will pass away just hearing the news" (male patient in his 40s).

\section{Critically ill PLHA lacked awareness of palliative care}

Among patients, it is also important to note that there was very little awareness of palliative care-even more educated patients had never heard the term. When the premise of palliative care was explained, patients reported being illiterate and ill-informed: "I am illiterate and haven't studied anything...so what will I understand, Sir?" (female caregiver in her 30s). When asked which factors were important in palliative care however, patients prioritised getting medicines on time, followed by food and accommodation: "most important of all, the patient should get the medicines timely, the treatment should be done well, the lodging and food...all these facilities should be good" (male patient in his 20s).

PLHA reported that many families did not want to leave the hospital due to a desire for active treatment and the persistence of hope: "the relatives don't want to take the patient home, because of the hope that is there in the hospital...perhaps if he had been in the hospital, he...can be saved by the treatment if the condition becomes worse. So, they want to live in the hospital mostly" (male patient in his 40s). In keeping with these expectations, PLHA reported that doctors typically kept actively treating patients even when they were dying.

\section{Experiences of patients' deaths and discharge procedures}

In general, witnessing patients' deaths was quite traumatic for other PLHA, which supported the thematic detailing the need for a dedicated palliative care area. There was limited space for grieving relatives and some patients felt like they had been rushed when their relative passed away: "like when he died, then and there within a few seconds, they called an ambulance and sent him onward to his home...they were only concerned with whatever paperwork was required to be done, they only hired and paid the ambulance and turned them away from there" (male teenager, relative of deceased patient). Relatives reported that they were screaming in grief in the hospital and were usually taken to another room away from the patient with limited time to grieve and limited counselling support. "When I was crying, the medical staff took me in another private room and I was left there by myself. I wanted someone to be there with me, but this is a hospital not my house- what can I say? Not many people were there because it was at night. Only my mother and I were in that room. What I wanted does not matter...what can be done about it now?" (woman in her 30s, relative of deceased patient).

Meanwhile, other PLHA admitted in the facility would occasionally become anxious on hearing these cries and attempt to console the patient to stop crying: "the problem with crying is that there are many kinds of patients admitted in the hospital. It can make people anxious or worried. It will cause problems to all of the patients" (female caregiver in her 40s). That being said, patients appreciated that ambulance services were arranged for them without payment, as this was not typically done in other facilities.

At other government facilities in Bihar, the situation was described as being even worse: "like in the [government] hospital...they said that they would only treat this patient when they give some money. Then only they will touch or treat the patient- they did not want to do anything for him...[after he died], some fat and big people started trying to move my husband's body. Right away, I threatened them and said: beware! I have people with me. So don't dare touch my patient" (woman in her 30s, relative of deceased patient).

\section{PLHA undergoing hospital-based palliative care require social support}

"The options are limited...I am confined to my bed all day long...if there are loved ones nearby, then sometimes I chat with them. Sometimes, I take a walk along the corridors with the help of my companions" (male patient in his 40 s). Some patients reported feeling socially isolated and 
bored after several days of admission: "we do nothing all day. When my husband comes and visits, I smile and laugh with him, but when he returns home, I feel all alone...my father is there, and I can't speak that much with him. I don't know. Everything is good, but I get a little bored here" (female patient in her 20s). When asked what could be provided to help pass the time, many patients hesitated to answer, stating that this was a hospital not a place for entertainment and they had no such expectations. After some probing however, several patients suggested that recreational activities such as a television, space to walk around or board games could be provided in the spaces to make them more patient-friendly.

An FGD with representatives from the National Coalition of People Living with HIV in India further illustrated that basic medical needs are not even met for PLHA at most government facilities around the state, let alone social support needs: "they will prescribe you something random and say get it from outside and eat it" (female PLHA in her 30s, National Coalition of PLHA in India). "We did some advocacy for one patient and met with the hospital superintendent, because they were not even willing to do the dressing for this person. They kept saying go home, go home. How can the doctors say this at a government hospital?" (female PLHA in her 30s, Patna Network for PLHA Society).

\section{Preference for home-based palliative care and other services}

According to some PLHA, dying patients should be sent home with medicines and proper guidance to be able to see their relatives: "such a patient should be sent homeshouldn't be hospitalized" (male patient in his 40s). They should be given financial assistance and a vehicle to return home and be with family members: "if she tries to get a vehicle on her own, she will face a lot of difficulty. Ambulance should be provided from here" (female caregiver in her 40s). Similarly, in accordance with most local and religious customs, relatives and patients alike noted a preference for home death over hospital-based deaths. "If the doctor knows they will no longer be able to save the patient, they should send him home. So, the patient can meet the rest of his family, talk to everyone, and die peacefully at home" (female caregiver in her 40 s). In general, existing government or private hospitals lack the capacity to implement home-based palliative care programmes, even at well-established cancer care centres. HIV care, by comparison, lags even further behind.

\section{DISCUSSION}

PLHA have complex care needs and require supportive palliative care services, which go beyond pain management and include exploring the patient's understanding of illness and prognosis, psychosocial support for patients and caregivers, and advance care planning. ${ }^{27} 28$ Our latent thematic analysis of qualitative data reveals a very poor understanding of the concept of palliative care among PLHA and their caregivers. However, patients were able to identify the importance of psychosocial counselling, the desire for privacy and dignity for terminal patients with social activities to prevent isolation, and a preference for home-based palliative care wherever possible. We also found that relatives of patients played an outsized role in influencing doctors and nurses to avoid divulging the nature of the disease and prognosis directly to patients. There were notable concerns among critically ill PLHA that transparent disclosure of prognosis may lead to fear or anxiety regarding end-of-life care, and itself worsen clinical outcomes.

This study was one of the only reports on HIV and palliative care from the Asian continent, but similar findings have been reported from other global contexts. For example, Uwimana and Struthers conducted a mixedmethods study with 306 participants in Rwanda and found that over $50 \%$ of healthcare professionals reported that they had not been trained in palliative care, while most PLHA had unmet palliative care needs, especially with respect to pain relief, symptom management, financial and nutritional support. Addressing unmet palliative care needs is critical to improving quality of life. ${ }^{29}$ Iwelunmor and Airhihenbuwa's study on cultural implications of death and loss from AIDS among women in South Africa found that negative perceptions of AIDS-related death were linked to the belief that HIV status represented a death sentence. ${ }^{30}$ PLHA in Bihar similarly reported a fear of death and a desire for active treatment as part of this qualitative study.

While Western bioethics values full disclosure between the doctor and patient, our findings indicate that other cultures may not be as welcome to this kind of transparency. There are notable differences in cultural norms and practices with respect to death and dying, especially in terms of patient-centred versus family-centred decisionmaking. ${ }^{31-33}$ Prior to the 20th century, even the American Medical Association's 1847 Code of Ethics stated: 'a physician should not be forward to make gloomy prognostications...the physician should be the minister of hope and comfort to the sick' ${ }^{34}$ By the 1970 s, the patient's right to know 'understandable information concerning diagnosis, treatment and prognosis', at least in Western societies, was more commonly understood. ${ }^{35}$ Having said this, one should not make assumptions regarding the information a patient wishes to receive about their condition or prognosis based on their cultural background. As it is difficult to predict an individual's preferences, it is important to explore with each patient how much and what type of information they wish to receive. Health providers should explore how much information the patient wishes to be disclosed to family members. Our results also found that patients perceived the providers' desire to continue treating the patient as a positive phenomenon, perhaps because end-of-life care was a difficult concept to understand or relate to among patients during the time of interview and patients maintained an obstinacy of hope. Previous anecdotal reports by patients and families (outside the scope of this study) indicated that some did 
not appreciate attempts at cardiopulmonary resuscitation. Other studies have explored how unnecessary therapeutic efforts to prolong life can often be detrimental to the dignity and well-being of patients. ${ }^{36} 37$

In order to improve care and treatment for critically ill PLHA, palliative care should be introduced and discussed early in the care process by a team of providers that is aware of the patient's history, needs and care plan. A separate tailor-made area addressing the specific needs should be provided to PLHA receiving palliative care, but extra care should be taken to ensure that patients and caregivers are regularly visited and recreational activities are provided to prevent isolation. The grieving process should allow patients to spend adequate time with the deceased in a private space without rushing them toward an ambulance or ushering them to a corner of the hospital. Healthcare providers should take precautions to ensure that a private space can also be provided for grieving relatives. Providers must also exercise greater caution in counselling relatives of critically ill PLHA regarding the disclosure of a poor prognosis, as they often have strong opinions which may conflict with the needs of the patient. Finally, home-based palliative care programmes should be expanded in Bihar, especially for this vulnerable group of PLHA, in order to respect the needs of terminal patients and relatives, many of whom prefer home deaths and normative cultural rituals over hospital-based deaths.

\section{Limitations}

Despite the broad variation of participants in the study, this study has several limitations. First, recall bias may have played a role in accurately describing encounters with hospital staff in the case of relatives of deceased patients. Second, while we achieved saturation in the qualitative study as a whole, we did not attain saturation in each individual subgroup of participants. This may have been a function of limited sample sizes in each demographic category (eg, five caregivers of hospitalised patients) even though the overall sample included 29 respondents. Finally, it is important to note that the sample size and geographical coverage of this study were limited.

\section{CONCLUSION}

PLHA in Bihar have several unmet needs with respect to palliative care services, which are limited in availability compared with services for patients with cancer. However, the mortality rates of patients with advanced HIV are well recognised to be extremely high, which, coupled with the substantial stigma associated with the condition, inevitably leads to an undignified and traumatic death. With improved awareness, a greater focus on patient-centric care and better resource allocation, the quality of endof-life care for this vulnerable group of patients could be drastically improved. Better understanding of cultural norms and patients' preference for information delivery regarding end-of-life care, including early establishment of the role of family members in decision-making, are key areas of improvement.

Acknowledgements We are very grateful for the contributions of Karishma Krishna Kurup, Chhavi Kumar, Rohit Kumar, Shweta Singh, and the Medecins Sans Frontieres field and capital coordination teams. We are grateful to Ria Roy, Pallavi Lohani, Anuradha Ratan, Apurv Agrawal, and all medical interns and residents at the All India Institute of Medical Sciences (Patna) for their support in the study.

Contributors AH, MN and SB conceptualised the study. MN and PK conducted the study, managed data collection and analysis. RM, AH and SB designed and reviewed data collection tools and revised the literature review. MN prepared the first draft of the manuscript. KR and LM-P further revised subsequent versions of the manuscript. All authors reviewed, edited and approved the final manuscript.

Funding The authors have not declared a specific grant for this research from any funding agency in the public, commercial or not-for-profit sectors.

Competing interests None declared.

Patient and public involvement Patients and/or the public were not involved in the design, or conduct, or reporting, or dissemination plans of this research.

Patient consent for publication Not required.

Ethics approval Ethics approval was obtained by the Medecins Sans Frontieres Ethics Review Board and the Institutional Ethics Committee at All India Institute of Medical Sciences, Patna.

Provenance and peer review Not commissioned; externally peer reviewed.

Data availability statement Data are available upon reasonable request. The data supporting the findings of this study/publication are retained at Medecins Sans Frontieres, New Delhi and will not be made openly accessible due to ethical and privacy concerns. Data can however be made available after approval of a motivated and written request to MSF at sakib.burza@barcelona.msf.org.

Open access This is an open access article distributed in accordance with the Creative Commons Attribution Non Commercial (CC BY-NC 4.0) license, which permits others to distribute, remix, adapt, build upon this work non-commercially, and license their derivative works on different terms, provided the original work is properly cited, appropriate credit is given, any changes made indicated, and the use is non-commercial. See: http://creativecommons.org/licenses/by-nc/4.0/.

\section{ORCID iDs}

Mohit Nair http://orcid.org/0000-0002-3410-8541

Raman Mahajan http://orcid.org/0000-0001-6788-2835

\section{REFERENCES}

1 National AIDS Control Organization. HIV Facts \& Figures, 2018. Available: http://naco.gov.in/hiv-facts-figures

2 List of ARTC, 2017. Available: http://pib.nic.in/newsite/PrintRelease. aspx? relid=161389

3 Gupta A. Bihar faces shortages of HIV drug, 2015. Available: https:// www.downtoearth.org.in/news/bihar-faces-shortage-of-hiv-drug42839

4 Nair M, Kumar P, Pandey S, et al. Refused and referred-persistent stigma and discrimination against people living with HIV/AIDS in Bihar: a qualitative study from India. BMJ Open 2019;9:e033790.

5 World Health Organization. Guidelines for managing advanced HIV disease and rapid initiation of antiretroviral therapy. Geneva: World Health Organization, 2017.

6 Biset Ayalew M. Mortality and its predictors among HIV infected patients taking antiretroviral treatment in Ethiopia: a systematic review. AIDS Res Treat 2017;2017:1-10.

7 Palliative Care Definition. International Association for Hospice \& Palliative Care. Available: https://hospicecare.com/what-we-do/ projects/consensus-based-definition-of-palliative-care/definition/

8 World Health Organization. Palliative care. HIV-AIDS. Available: https://www.who.int/hiv/topics/palliative/PalliativeCare/en/

9 Swami M, Case AA. Effective palliative care: what is involved? Oncology 2018;32:180-4.

10 Kumar SK. Kerala, India: a regional community-based palliative care model. J Pain Symptom Manage 2007;33:623-7.

11 McDermott E, Selman L, Wright M, et al. Hospice and palliative care development in India: a multimethod review of services and experiences. J Pain Symptom Manage 2008;35:583-93. 
12 Khosla D, Patel FD, Sharma SC. Palliative care in India: current progress and future needs. Indian J Palliat Care 2012;18:149.

13 Joranson DE, Rajagopal MR, Gilson AM. Improving access to opioid analgesics for palliative care in India. J Pain Symptom Manage 2002;24:152-9.

14 Ramasamy Venkatasalu M, Sirala Jagadeesh N, Elavally S, et al. Public, patient and carers' views on palliative and end-of-life care in India. Int Nurs Rev 2018;65:292-301.

15 McGrath P, Holewa H, Koilparampil T, et al. Learning from each other: cross-cultural insights on palliative care in Indian and Australian regions. Int J Palliat Nurs 2009;15:499-509.

16 Rajagopal MR, Palat G. Kerala, India: status of cancer pain relief and palliative care. J Pain Symptom Manage 2002;24:191-3.

17 Seamark D, Ajithakumari K, Burn G, et al. Palliative care in India. J R Soc Med 2000;93:292-5.

18 Paleri A, Numpeli M. The evolution of palliative care programmes in North Kerala. Indian J Palliat Care 2005;11:15.

19 Sankaran BM, Chakraborty S, Patil VM, et al. Burden and outcomes of pressure ulcers in cancer patients receiving the Kerala model of home based palliative care in India: results from a prospective observational study. Indian J Palliat Care 2015;21:152.

20 Thayyil J, Cherumanalil J. Assessment of status of patients receiving palliative home care and services provided in a rural area-Kerala, India. Indian J Palliat Care 2012;18:213.

21 Lloyd J, Pinto AM, Nair S, et al. A qualitative study on palliative needs of stroke patients in an indian tertiary care setting - doctors' perspective. Indian J Palliat Care 2019;25:84

22 Joseph N, Jayarama S, Kotian S. A comparative study to assess the awareness of palliative care between urban and rural areas of Ernakulum district, Kerala, India. Indian J Palliat Care 2009;15:122.

23 Gopal KS. Knowledge and attitude about palliative care, in general, population and health care professionals in tertiary care hospital. International Journal Of Scientific Study 2016;3:31-5.

24 Too W, Watson M, Harding R, et al. Living with AIDS in Uganda: a qualitative study of patients' and families' experiences following referral to hospice. BMC Palliat Care 2015;14:67.
25 Harding R. Palliative care as an essential component of the HIV care continuum. Lancet HIV 2018;5:e524-30.

26 Merlins JS, Tucker RO, Saag MS, et al. The role of palliative care in the current HIV treatment era in developed countries. Top Antivir Med 2013;21:20

27 World Health Organization. Policy on palliative care in HIV/AIDS. Available: http://www.who.int/hiv/topics/palliative/PalliativeCare/ en/

28 Joint United Nations progam on HIV/AIDS (UNAIDS). Aids palliative care: a technical update. Geneva: UNAIDS, 2000. http://data.unaids. org/Publications/IRC-pub05/JC453-PalliCare-TU en.pdf

29 Uwimana J, Struthers P. Met and unmet palliative care needs of people living with HIV/AIDS in Rwanda. Sahara J 2007;4:575-85.

30 Iwelunmor J, Airhihenbuwa CO. Cultural implications of death and loss from AIDS among women in South Africa. Death Stud 2012;36:134-51.

31 Blackhall LJet al. Ethnicity and attitudes toward patient autonomy. JAMA 1995;274:820.

32 Dohan D, Levintova M. Barriers beyond words: cancer, culture, and translation in a community of Russian speakers. $J$ Gen Intern Med 2007;22 Suppl 2:300-5.

33 Lo B, Quill T, Tulsky J. Discussing palliative care with patients. ACP-ASIM end-of-life care consensus panel. American College of Physicians-American Society of internal medicine. Ann Intern Med 1999;130:744.

34 Sisk B, Frankel R, Kodish E, et al. The truth about truth-telling in American medicine: a brief history. Perm J 2016;20:15-219.

35 American Hospital Association. A patient's bill of rights [Internet]. Chicago, IL: American Hospital Association, 1973. www.carroll.edu/ msmillie/bioethics/patbillofrights.htm

36 Dantas MMF, Amazonas MCLdeA. The illness experience: palliative care given the impossibility of healing. Rev Esc Enferm USP 2016;50 Spec:47-53.

37 Baena Álvarez C. Limitation of therapeutic effort: when less is more. Colomb Med 2015;46:1-2. 